\title{
Impact of an educational debate on the knowledge of college students on opioids, and factors affecting their perception about addiction
}

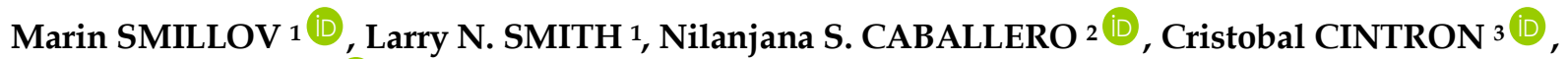 \\ Hale Z. TOKLU 2,3,4* (D)
}

1 Humanities and Foreign Languages, Santa Fe College, FL, USA.

2 Sciences for Health Programs, Santa Fe College, FL, USA.

3 HCA Graduate Medical Education, North Florida Division, FL, USA.

4 College of Medicine, University of Central Florida, FL, USA.

* Corresponding Author. E-mail: hale.toklu@sfcollege.edu (H.Z.T.); Tel. +13523955954.

Received: 19 December 2018 / Revised: 09 February 2019 / Accepted: 24 February 2019

\begin{abstract}
The prescription and illicit use of opioids has greatly increased over the past 2 decades leading to what is currently recognized as the opioid epidemic. In this study, we evaluated the impact of an educational event on the perceptions of college students about opioid use and addiction. A survey was given to 61 students in a community college. The responses of the students who attended the conference $(n=31)$ were compared with those who did not attend $(n=30)$. All the respondents, regardless of the conference attendance, agreed that the opioid use is a serious problem for the community and the individual. Students stated that single use of opioids does not cause addiction (control 59\% vs intervention 41\%). Overall, $80 \%$ of the students agreed that short term use of opioids can cause addiction; however, almost half of these ( $43 \%$ ) believed that they will not be addicted after a short term use. There was no significant difference between the two groups. However, the students younger than 25 were two times more likely to believe that they will not be addicted after a short term use of opioids (OR 2.1). This was lower among the students who attended the educational session. Furthermore, educational session significantly $(\mathrm{p}=0.02)$ increased their knowledge of opioids ( $45 \%$ vs $55 \%$ in the intervention group answered the question correctly). Even though the sample size is too small to draw a generalized conclusion, the present findings demonstrate the importance of the educational activities in increasing awareness towards opioid use and abuse.
\end{abstract}

KEYWORDS: Opioids; college; students; perception; awareness; addiction; education.

\section{INTRODUCTION}

Long-term use of prescription opioids can lead to tolerance, and the need for higher and/or more frequent doses of the drug to get the desired effects. Drug addiction is a chronic disease resulting from drug dependence; and characterized by compulsive, or uncontrollable, drug seeking behaviour [1].

The term "opioid epidemic" is widely used by politicians and the media in reference to the current situation of health crisis in the United States. This is not an exaggeration but a realistic assessment of a scary reality. On October 26, 2017, President Trump declared the opioid crisis as a Public Health Emergency. On March 19, 2018, the administration unveiled a new website, CrisisNextDoor.gov, where Americans can share their stories and experiences with the opioid addiction. The opioid crisis is being addressed at the highest levels of the US Government. In November of 2017, the Council of Economic Advisors (CEA) published a report entitled 'The Underestimated Cost of the Opioid Crisis'. According to this report, the deaths due to opioid overdose have increase $400 \%$ in the period from 1999 to 2015. In 2015, over 33,000 Americans died from a drug overdose involving opioids. The CEA estimates the economic cost of the opioid crisis at \$ 504 billion [2].

Behind the numbers are many untold stories of ruined lives, tragic deaths, and human suffering. According to Shatterproof, a national non-for-profit organization dedicated exclusively to combating the opioid crisis, one in three American families are directly affected by the drug abuse epidemic. The condition of every addict impacts directly four other people. By accounting for the legal costs of the drug epidemic and

How to cite this article: Smillov M, Smith L, Caballero N, Cintron C, Toklu HZ. Impact of an educational debate on the knowledge of college students on opioids, and factors affecting their perception about addiction. J Res Pharm. 2019; 23(5): 792-796. 
lost productivity, the estimated annual cost of the opioid crisis exceeds $\$ 700$ billion. The Center for Disease Control proclaimed that this is the "worst drug overdose epidemic in [US] history" [3].

A multi-disciplinary team of scholars at Santa Fe College engaged in a collaborative analysis of the attitudes towards opioid use in history. While acknowledging that the reasons for the current opioid crisis are complex, the team focused on the evolution of social views on opioids. In antiquity, people attributed supernatural origin to the powers of opioids. Opioids were used not only for medicinal purposed but also as means to control segments of the population and to attain political goals. In the post-Medieval period of modern science, the use of opioids was demystified and they were commonly viewed as panacea, i.e., cure for all. In the 19th century, opioids were used widely among all segments of the population and this use found prominent representations in opioid-inspired literature. It was not until the early part of the MS20th century, when governments began to realize to negative consequences of opioid addiction. The latter part of the 20th century was marked by acceptance and even glamorization of the opioid use. In this context, it should not be surprising that the beginning of the 21st century became the period of unprecedented opioid crisis.

The aim of the study was to deliver an educational session to the college students to increase awareness about opioids in terms of medical use versus nonmedical use, addiction and consequences of addiction to the individual and to the society. Meanwhile we evaluated their perceptions on opioid use. In order to see the effect of the training, we have conducted a short survey with the students and compared the responses of the students who attended the educational activity versus those who did not attend.

\section{RESULTS}

A total of 61 students participated in the survey. The sociodemographical characteristics of students are given in Table 1.

Table 1. The demographics of students $(n=61)$.

\begin{tabular}{|c|c|c|c|c|c|}
\hline & & Control & Intervention & Total & $\begin{array}{l}\text { Pearson } \\
\text { chi-square }\end{array}$ \\
\hline \multirow[t]{3}{*}{ Sex } & Male & $16(53.3)$ & $14(45.2)$ & $31(100.0)$ & \multirow[t]{2}{*}{0.523} \\
\hline & Female & $14(46.7)$ & $17(54.8)$ & $30(100.0)$ & \\
\hline & Total & $30(100.0)$ & $31(100.0)$ & $61(100.0)$ & \\
\hline \multirow[t]{3}{*}{ Age } & $\leq 25$ & $27(90.0)$ & $21(67.7)$ & $48(100.0)$ & \multirow[t]{2}{*}{0.04} \\
\hline & $>25$ & $3 \quad(10.0)$ & $10(32.3)$ & $13(100.0)$ & \\
\hline & Total & $30(100.0)$ & $31(100.0)$ & $61(100.0)$ & \\
\hline \multirow[t]{5}{*}{ Race } & White & $24(80.0)$ & $27(87.1)$ & $51(100.0)$ & \multirow[t]{4}{*}{0.540} \\
\hline & Black/ African American & $4(13.3)$ & $4 \quad(12.9)$ & $8(100.0)$ & \\
\hline & American Indian/ Alaska native & $1(3.3)$ & 0 & $1(100.0)$ & \\
\hline & Asian & $1(3.3)$ & 0 & $1100.0)$ & \\
\hline & Total & $30(100.0)$ & $31(100.0)$ & $61(100.0)$ & \\
\hline \multirow[t]{3}{*}{ Ethnicity } & Hispanic or Latino or Spanish origin & $11(45.8)$ & $13(54.2)$ & $24(100.0)$ & \multirow[t]{2}{*}{0.674} \\
\hline & Not Hispanic or Latino or Spanish origin & $19(51.4)$ & $18(48.7)$ & $37(100.0)$ & \\
\hline & Total & $30(100.0)$ & $31(100)$ & $61(100.0)$ & \\
\hline
\end{tabular}

The $45 \%$ percent of the control group answered the question about which drugs are considered opioids correctly, while this ratio was significantly $(\mathrm{p}=0.02)$ higher $(55 \%)$ in the intervention group.

All the students $(100 \%)$ regardless of the conference attendance agree that the 'opioid use is a serious problem for the community'. Also, $98 \%$ agree that the 'opioid use is a serious problem for the individual'.

Students stated that single use of opioids does not cause addiction (control $59 \%$ vs intervention $41 \%$ ). Overall, $80 \%$ of the students agreed that short term use of opioids can cause addiction; however, almost half of these believe that they will not be addicted after a short term use (Figure 1). Both groups state that opioids may cause addiction even after a short term use (control $47 \%$ vs intervention 53\%). However, $58 \%$ in the control group and $42 \%$ in the intervention group believe that they will not be addicted after a short term use of opioids. The difference between the two groups were not significant $(\mathrm{p}>0.05)$. 


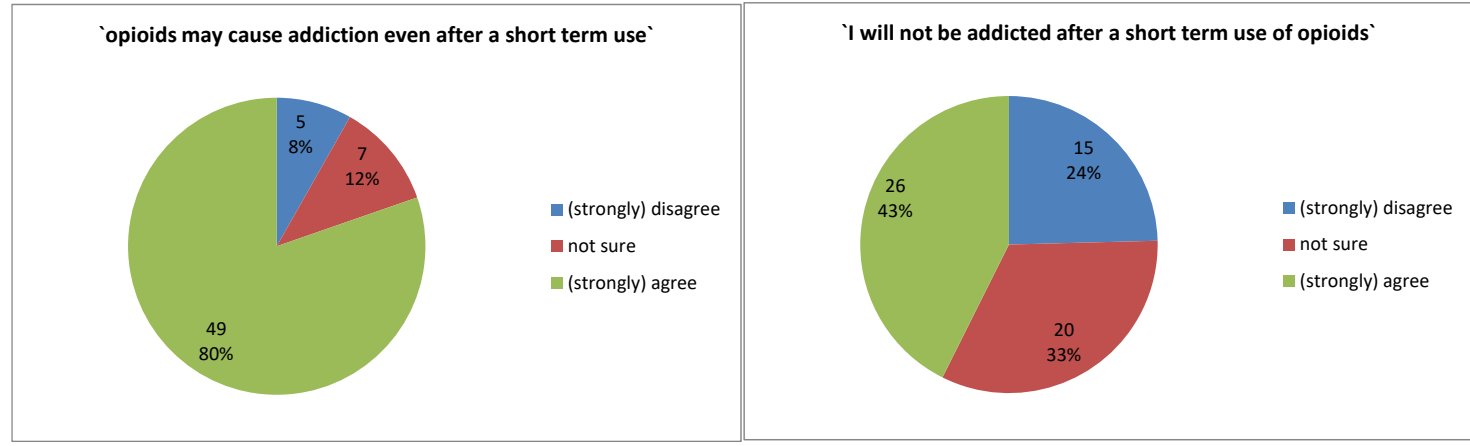

Figure 1. The students' opinions about opioid addiction with short term use $(n=61)$.

We interpreted the students' belief that they will not be addicted (even though they admit that opioid use may be addictive and others can be addicted) as `self-confidence'; and further analysed if it was affected by exposure to the educational event. The factors such as age, sex and ethnicity were also investigated (Table 2). In our study, we found that the age and ethnicity were precipitating factors, i.e. Students younger than 25 are almost two times more likely to believe that they will not be addicted after a short term use of opioids. Hispanics/Latino/Spanish origin were 2.3 times more likely to believe that they will not be addicted after a short term use. The ratios were lower among the students who attended the educational session.

Table 2. Factors associated with the belief that they will not be addicted with short term use of opioids (selfconfidence) and exposure to the educational session $(n=61)$.

\begin{tabular}{|c|c|c|c|c|c|}
\hline & $\begin{array}{l}\text { Self-confidence / } \\
\text { Exposure (Yes) }\end{array}$ & $\begin{array}{l}\text { Self-confidence / } \\
\text { Exposure (No) }\end{array}$ & OR & $\begin{array}{c}2 \text { Tail } \\
\text { p-value }\end{array}$ & $\mathbf{N}$ \\
\hline$\leq 25$ agree vs disagree & $81 \%$ & $66 \%$ & 2.10 & 0.31 & $n=41$ \\
\hline$>25$ agree vs disagree & $19 \%$ & $33 \%$ & & & \\
\hline Males agree vs Females agree & $57 \%$ & $42 \%$ & 1.19 & 0.78 & $n=41$ \\
\hline $\begin{array}{l}\text { Males disagree vs Females } \\
\text { disagree }\end{array}$ & $53 \%$ & $46 \%$ & & & \\
\hline $\begin{array}{l}\text { Hispanic/Latino/ Spanish } \\
\text { origin agree vs disagree }\end{array}$ & $65 \%$ & $44 \%$ & 2.37 & 0.12 & $n=61$ \\
\hline $\begin{array}{l}\text { Not Hispanic/Latino/Spanish } \\
\text { origin agree vs disagree }\end{array}$ & $35 \%$ & $56 \%$ & & & \\
\hline
\end{tabular}

*20 participants responded as `not sure`.

\section{DISCUSSION}

Many factors, both individual and environmental, contribute to drug addiction. The addiction is mainly associated with social factors and the length of use. However, it is difficult to predict who's vulnerable to eventual dependence on and abuse of these drugs [1]. Even short term opioid use can lead to addiction. Both, prescription and illicit use of opioids can exhibit a risk of developing addiction. Prescription opioids and heroin have chemically similar structure; and in a study, nearly 80 percent of Americans using heroin (including those in treatment) reported misusing prescription opioids prior to using heroin [4].

In a survey study with university students, they reported stimulants as the most commonly used prescription drug for nonmedical reasons, least expensive, and easiest to obtain on campus, followed by benzodiazepines. Opioids were less commonly used, more expensive, and difficult to acquire [5]. On the other hand, a more recent study with teen-agers demonstrated that $21 \%$ of the study participants reported nonmedical use of prescription opioids at least once in lifetime [6]. On the other hand, in another study, lifetime prevalence of prescription opioid misuse was found 9.5\%. Primary reasons for misuse were pain relief (33.9\%), "to feel good/get high" (23.2\%) and experimenting (21.4\%) [7].

General population surveys conducted in the US, Canada and Australia, has found that the non-medical use of pharmaceutical opioids is in the second place following the illicit use of cannabis [8]. In the US, the nonmedical use of pharmaceutical opioids has been estimated to cost over $\$ 70$ billion annually. A metaanalysis which ids published in 2018, has found that pharmaceutical opioids, sedatives and stimulants for nonmedical use are primarily sourced through informal exchanges between friends and family [9]. 
As the educators, we aimed to increase awareness about opioid crisis and at the same explore the students` knowledge and perception on addiction with opioids. Our multidisciplinary team made a presentation to a random group of college students on the evolution of the opioids use and their proven detrimental effects on human health. The presentation was followed by a questions and answers session. In order to see the effect of the training, we have conducted a short survey afterwards and compared their responses with those who did not attend.

All the respondents, regardless of the conference attendance, agreed that the opioid use is a serious problem for the community and the individual. We observed that educational session significantly increased their knowledge of opioids ( $45 \%$ vs 55\% in the intervention group answered the question correctly).

The students stated that single term use of opioids does not cause addiction ( $59 \%$ in control vs $41 \%$ in intervention). On the other hand, $80 \%$ of the students agreed that short term use of opioids can cause addiction; however, almost half of these (43\%) believed that they will not be addicted after a short term use. We think that this finding is striking and may reflect their self-confidence for not being addicted. There was no significant difference between the two groups. However, the students younger than 25 were two times more likely to believe that they will not be addicted after a short term use of opioids. This was slightly lower among the students who attended the educational session.

\section{CONCLUSION}

Even though the sample size is too small to draw a generalized conclusion, the present findings demonstrate the importance of the educational activities in increasing awareness towards opioid use and abuse.

\section{MATERIALS AND METHODS}

A total of 61 community college students who consented to participate in the study were given a survey in March 2018. The anonymous survey consisted of 13 structured questions. The responses of the students who attended the educational debate (intervention group; $n=31$ ) were compared with those who did not attend (control group; $\mathrm{n}=30$ ). The educational intervention was a 2 hours educational session to random students that consisted of three sections which aimed to provide information on opioids and their mechanisms of action, medical use and abuse, consequences of addiction. The presentation was followed by a questions and answers session and debate. At the end of the educational sessions, students were asked to complete an anonymous survey. Another random group of college students who did not attend the educational session, were asked to fill out the surveys on the same day as the control group.

Ethics: The IRB approval was obtained from Santa Fe College Institutional Review Board.

Statistical analysis: The statistical analysis was performed using IBM SPSS Statistics Software for Windows version 24 (IBM Corp, Armonk, NY, USA). P $<0.05$ was considered as statistically significant.

Acknowledgements: Prof. Bill Stephenson, the Chair of Humanities and Foreign Languages and Prof. David Tegeder, the Chair of Social and Behavioral Sciences. Cristobal Cintron for his biostatistical assistance.

Author contributions: Concept - M.S., H.T., N.C, L.S.; Design - M.S., H.T.; Supervision - H.T.; Data Collection and/or Processing - N.C.; Analysis and/or Interpretation - H.T., C.C.; Literature Search -H.T., M.S.; Writing -, H.T., M.S.; Critical Reviews - M.S., L.S., N.C., C.C., H.T.

Conflict of interest statement: The authors declared no conflict of interest.

Disclaimer: This research was supported (in whole or in part) by HCA Healthcare and/or an HCA Healthcare affiliated entity. The views expressed in this publication represent those of the author(s) and do not necessarily represent the official views of HCA Healthcare or any of its affiliated entities.

\section{REFERENCES}

[1] Kosten TR, George TP. The neurobiology of opioid dependence: implications for treatment. Sci Pract Perspect. 2002; $1(1): 13-20$

[2] Council of Economic A. The underestimated cost of the opioid crisis. 2017 (https://www.whitehouse.gov/ briefingsstatements/cea-report-underestimated-cost-opioid-crisis/ accessed on February $5^{\text {th }}, 2019$ ). 
[3] https://www.drugabuse.gov/publications/drugs-brains-behavior-science-addiction (accessed on February 5th, 2019).

[4] Jones CM, Muhuri PK, Lurie PG. Trends in the nonmedical use of OxyContin, United States, 2006 to 2013. Clin J Pain. 2017; 33(5): 452-461. [CrossRef]

[5] Parks KA, Levonyan-Radloff K, Przybyla SM, Darrow S, Muraven M, Hequembourg A. University student perceptions about the motives for and consequences of nonmedical use of prescription drugs (NMUPD). J Am Coll Health. 2017; 65(7): 457-465. [CrossRef]

[6] Patry E, Bratberg JP, Buchanan A, Paiva AL, Balestrieri S, Matson KL. Rx for addiction and medication safety: An evaluation of teen education for opioid misuse prevention. Res Social Adm Pharm. 2018; pii: 1551-7411(18)30287-0. [CrossRef]

[7] Kenne DR, Hamilton K, Birmingham L, Oglesby WH, Fischbein RL, Delahanty DL. Perceptions of harm and reasons for misuse of prescription opioid drugs and reasons for not seeking treatment for physical or emotional pain among a sample of college students. Subst Use Misuse. 2017; 52(1): 92-99. [CrossRef]

[8] Hulme S, Bright D, Nielsen S. The source and diversion of pharmaceutical drugs for non-medical use: A systematic review and meta-analysis. Drug Alcohol Depend. 2018; 186: 242-256. [CrossRef]

This is an open access article which is publicly available on our journal's website under Institutional Repository at http://dspace.marmara.edu.tr. 